\title{
ADAPTACIÓN DE UNA COCINA INDUSTRIAL DE GAS LICUADO DE PETRÓLEO A BIOGÁS
}

\section{ADAPTATION OF AN INDUSTRIAL KITCHEN FROM LIQUEFIED PETROLEUM GAS TO BIOGAS}

\author{
María Teresa Castillo Rayo \\ Carlos José Izaba Umaña ${ }^{2}$
}

(Recibido/received: 30-noviembre-2020; aceptado/accepted:22-marzo-2021)

\begin{abstract}
RESUMEN: En este trabajo de investigación, se presenta la adaptación de una cocina industrial de gas licuado de petróleo a funcionar con biogás. Para la obtención del biogás se instaló un biodigestor semicontinuo de $12 \mathrm{~m}^{3}$, cargado con desechos orgánicos. Se realizó la evaluación técnica de la cocina, el diagnóstico, el diseño para su adaptación y las modificaciones de piezas requeridas para su funcionabilidad. Además, se comparó la eficiencia del gas licuado de petróleo y el biogás haciendo uso del método estadístico de análisis de variancia bifactorial con interacción. Se logró determinar que el gas licuado de petróleo es más eficiente que el biogás, sin embargo, el biogás es mucho más amigable con el medio ambiente, ya que evita el uso indiscriminado de leña, disminuye los costos de gas licuado de petróleo y consumo de este. Además, de salvaguardar la salud respiratoria de los trabajadores.
\end{abstract}

PALABRAS CLAVES: Biogás; gas licuado de petróleo; cocina industrial; biodigestor.

ABSTRACT: In this research work, the adaptation of an industrial liquefied petroleum gas cooker to run on biogas is presented. To obtain the biogas, a $12 \mathrm{~m} 3$ semi-continuous biodigester was installed, loaded with organic waste. The technical evaluation of the kitchen, the diagnosis, the design for its adaptation and the modifications of parts required for its functionality were carried out. In addition, the efficiency of liquefied petroleum gas and biogas was compared using the statistical method of analysis of two-factorial variance with interaction. It was determined that liquefied petroleum gas is more efficient than biogas, however, biogas is much more environmentally friendly, since it avoids the indiscriminate use of firewood, reduces the costs of liquefied petroleum gas and consumption of this. In addition, to safeguard the respiratory health of workers

${ }^{1}$ Universidad Nacional de Ingeniería, Recinto Pedro Arauz Palacio, Facultad de Tecnología de la Industria. Departamento de energética. ORCID:https://orcid.org//0000-9241-6200,

E-mail:maria.castillo@fti.uni.edu.ni

2 Universidad Nacional de Ingeniería, E-mail: cjumanai@gmail.com 
KEYWORDS: Biogas; Petroleum liquid gas; industrial kitchen; biodigester.

\author{
ABREVIATURAS: \\ RUPAP: Recinto Universitario Pedro Aráuz Palacios \\ GLP: Gas licuado de petróleo \\ GTZ: Cooperación Técnica Alemana \\ SNV: Sistema Nacional de Voluntariado Holandés \\ TR: Tiempo de retención \\ DBO: Demanda biológica de oxígeno \\ DQO: Demanda química de oxígeno \\ TMF: Tiempo final \\ TPF: Tipos de combustibles. \\ $\mathrm{H}_{2} \mathrm{~S}$ : Ácido sulfhídrico
}

\title{
INTRODUCCIÓN
}

Las cocinas industriales son utilizadas para la cocción de alimentos a grandes escalas, en todo el mundo. Siendo las más comunes las de uso comercial, las cuales tienden a consumir grandes cantidades de gas licuado de petróleo afectando el medio ambiente circundante debido a las emisiones de gases de efecto invernadero. Por lo tanto, es necesario el uso de fuentes alternas de energía amigables al medioambiente tales como el biogás.

El biogás es el producto principal de la digestión anaerobia, proceso biológico degradativo en el cual parte de los materiales orgánicos de un sustrato son convertidos en una mezcla de Dióxido de carbono $\left(\mathrm{CO}_{2}\right)$, hidrógeno, metano, sulfuro de hidrógeno y trazas de otros elementos. En este interviene un consorcio de bacterias y arqueas metanógenas, estas últimas muy sensibles al oxígeno. De ahí que este proceso sea estrictamente anaerobio. En comparación con las digestiones aerobias, la fermentación anaerobia permite convertir gran cantidad de residuos, efluentes de las industrias papelera, alimentaria, fermentativa y química, en energía, al transformar casi totalmente la carga contaminante en metano (Ferrer, Yoandy, Pérez, 2010).

Desde hace muchos siglos, la producción de biogás se realiza en países como China y la India (Werner, 1983). Esta producción de biogás se da por la fermentación anaeróbica, es un proceso en ausencia de oxígeno dentro de recipientes denominados digestores, también se da la fermentación natural, la cual consiste en un proceso biológico natural donde se descompone la materia orgánica. En ambas, se encuentran involucrados gases como metano, dióxido de carbono, hidrógeno. La fermentación anaeróbica transcurre con menor desprendimiento calorífico, circunstancia que determina un mayor contenido energético y un incremento en la retención de nitrógeno original de los residuos digeridos (Singh, 1974). Este proceso se realiza en varias etapas por diferentes tipos de especies bacterianas, productoras o no de metano, que contribuyen de algún modo a la formación de este gas. 
En Nicaragua el manejo de los desechos orgánicos de los animales ha sido un problema por muchas décadas, puesto que son arrojados en las afueras de las poblaciones o cercana a caseríos donde existes basureros no autorizados, produciendo contaminación ambiental por la descomposición química de estos y problemas respiratorios a los habitantes al no dar el tratamiento adecuado. La tecnología del biogás está disponible en Nicaragua desde mediados del siglo XX donde la Corporación Técnica Alemana (GTZ) y el Sistema Nacional de Voluntariado (SNV), entre otras organizaciones como el Grupo Fénix, (Grupo formado en la Universidad Nacional de Ingeniería, que actualmente es auto sostenible) incluyeron en su plan la diseminación de la tecnología del biogás. De este modo se han ejecutado proyectos que funcionan en diferentes zonas del país, desde pequeños biodigestores caseros de bajo costo hasta algunas industrias que los tienen en operación.

En los años 90, en la Universidad Nacional de Ingeniería, Recinto Universitario Pedro Aráuz Palacios (RUPAP), inició un proyecto con dos biodigestores, uno de campana flotante y otro de campana fija, con ayuda de la cooperación sueca, SWISSCONTACT, sin embargo, el proyecto fue descontinuado y los biodigestores quedaron en desuso. En el año 2010, se habilitó el laboratorio de biomasa donado por la Universidad Carlos 3 de Madrid España, se construyeron y colocaron dos biodigestores de tipo Batch, tres biodigestores a temperatura ambiente, y dos biodigestores en camisa de agua.(Luis-Rodríguez, 2010) En abril 2017 se instaló un Biodigestor de tipo Tubular, para la producción de biogás del comedor de la cocina del RUPAP.

Empresas como Tecnosol, distribuían cocinas que trabajan con biogás, las cuales se incluían dentro del paquete de venta del biodigestor; ese mercado de biodigestores está dado por la empresa Biobolsa de México, quien en conjunto con el Servicio de voluntariado holandés (SNV), implementaron el desarrollo del programa de biogás en Nicaragua en conjunto con el fondo multilateral de inversiones, miembros del grupo BIP. El proyecto se ejecutó entre 2012 y 2017(SNV, n.d.)

Conscientes de la problemática que implica el uso indiscriminado tanto de la leña como del gas licuado de petróleo, GLP, se decidió desarrollar un proyecto para contribuir al uso racional de los mismos y disminuir la contaminación ambiental promoviendo el uso del biogás y la reducción del uso de combustibles fósiles, este proyecto estudio tuvo como objetivo principal, adaptar una cocina que funciona inicialmente con GLP a biogás, mediante el aprovechamiento de las excretas de ganado vacuno como combustible obtenido de un biodigestor semicontinuo de tipo tubular. También realizar pruebas con las variables temperatura y tiempo para determinar si existe una significancia estadística con respecto a los tipos de combustibles objeto de estudio.

\section{METODOLOGÍA}

A continuación, se expone la metodología experimental llevada a cabo en este estudio desde la instalación del biodigestor para la obtención del biogás, las modificaciones realizadas para la rehabilitación de la cocina industrial, así como las herramientas estadísticas utilizados en las pruebas de funcionamiento que ayudó a determinar la eficiencia del biogás frente al GLP. 
Instalación de biodigestor

El biodigestor de flujo semicontinuo tipo tubular de $12 \mathrm{~m}^{3}$ donado por la empresa Tecnosol, fue instalado cerca de las instalaciones del comedor del Recinto Universitario Pedro Arauz Palacios (RUPAP), perteneciente a la Universidad Nacional de Ingeniería (UNI), situada en el municipio de Managua, Nicaragua a $12^{\circ} 08^{\prime} 11.7^{\prime \prime} \mathrm{N}-86^{\circ} 13^{\prime} 25.0^{\prime \prime} \mathrm{W}$

El sistema estaba compuesto por válvulas de apertura y cierre, mangueras de paso de gas, válvulas de paso de gas, filtro para limpiar el ácido sulfhídrico $\mathrm{H}_{2} \mathrm{~S}$, biobolsa, lona de protección para la biobolsa, parches de reparación y dos quemadores de repuesto (figura 1). Este tipo de sistema es de fácil manejo y de bajo costo. Según especificaciones, este biodigestor tiene la capacidad de producir $3.60 \mathrm{~m}^{3}$ de biogás al día, trabajando con un quemador 7.5 horas diarias y 3.75 horas con dos quemadores.

La biobolsa está elaborada de polietileno. Este biodigestor posee un ducto de entrada a través del cual se suministra la materia orgánica, en este caso se utilizó excretas de ganado vacuno y agua. La porción por introducir en la biobolsa es de 1:3, es decir una porción de excretas por tres partes de agua.

El principio de funcionamiento es muy sencillo, los sustratos son alimentados por la tubería de entrada y ocupan la parte inferior de la bolsa mientras que el tope sirve como contenedor del biogás generado durante la operación. La presión de trabajo es usualmente alcanzada colocando pesos sobre la bolsa. Una vez digerido el sustrato alimentado, el digestato abandona la bolsa por la tubería de salida (Barrera-Cardoso1 et al., 2020).

Por su origen biológico se lo conoce mundialmente como biogás, que es una mezcla de gases conteniendo metano (50 a 70\%), anhídrido carbónico (30 a 45\%), hidrógeno (1 a 3\%), oxígeno $(0,5$ a $1 \%)$, gases diversos (1 a 5\%) y vestigios de anhídrido sulfuroso.(Antonio \& Aguilera, 2017) Se consideran tres rangos de temperatura para los sistemas de biogás anaeróbico: psicrófilos (de 15 a $25^{\circ} \mathrm{C}$ ), mesófilos (de 30 a $38^{\circ} \mathrm{C}$ ), y termófilos (de 50 a $60^{\circ} \mathrm{C}$ ). Estos rangos de temperatura facilitan el crecimiento de microbios específicos. Los sistemas termófilos son más sensibles a cambios medioambientales, tales como las fluctuaciones de temperatura y las concentraciones químicas producidas durante el proceso de digestión y es que el número de especies de microorganismos funcionales que sobreviven a estas temperaturas es considerablemente menor que aquellos que sobreviven a temperaturas más bajas. Por debajo de los $15^{\circ} \mathrm{C}$ la producción de biogás se reduce significativamente y el monóxido de carbono (CO) se convierte en el producto 2 dominante de la digestión anaeróbica; por lo tanto, los sistemas de digestión anaeróbica no son recomendados para lugares con una temperatura por debajo de este límite, sin la adición de calor y control de temperatura (Barrena et al., 2014).

El tiempo de retención (TR) es el tiempo en que las bacterias dentro del digestor son degradadas en condiciones anaeróbicas, es decir en ausencia de oxígeno (Miguel Barrena , Jóhmer Julca , Monika Hellenthal, 2017). EI TR en esta investigación fue de 15 a 35 días, esta variación depende de la temperatura atmosférica que se presente en el momento de la carga. 
El material ya digerido (biogás) por acción bacteriana abandona el biodigestor mediante el ducto de salida hacia la cocina industrial.

El biogás está compuesto principalmente por 55 - 70\% de metano $\left(\mathrm{CH}_{4}\right), 30-45 \%$ de dióxido de carbono $\left(\mathrm{CO}_{2}\right)$ y trazas de otros gases. El biogás puede ser empleado como combustible en: cocinas, calefacción, iluminación, generadores eléctricos, etc. La producción de biogás en un digestor depende de diferentes factores: la temperatura, el tiempo de retención hidráulico, las bacterias, la relación carbono y nitrógeno, el pH, el contenido de sólidos y el contenido de sustancias tóxicas (Barrera-Cardoso1 et al., 2020).

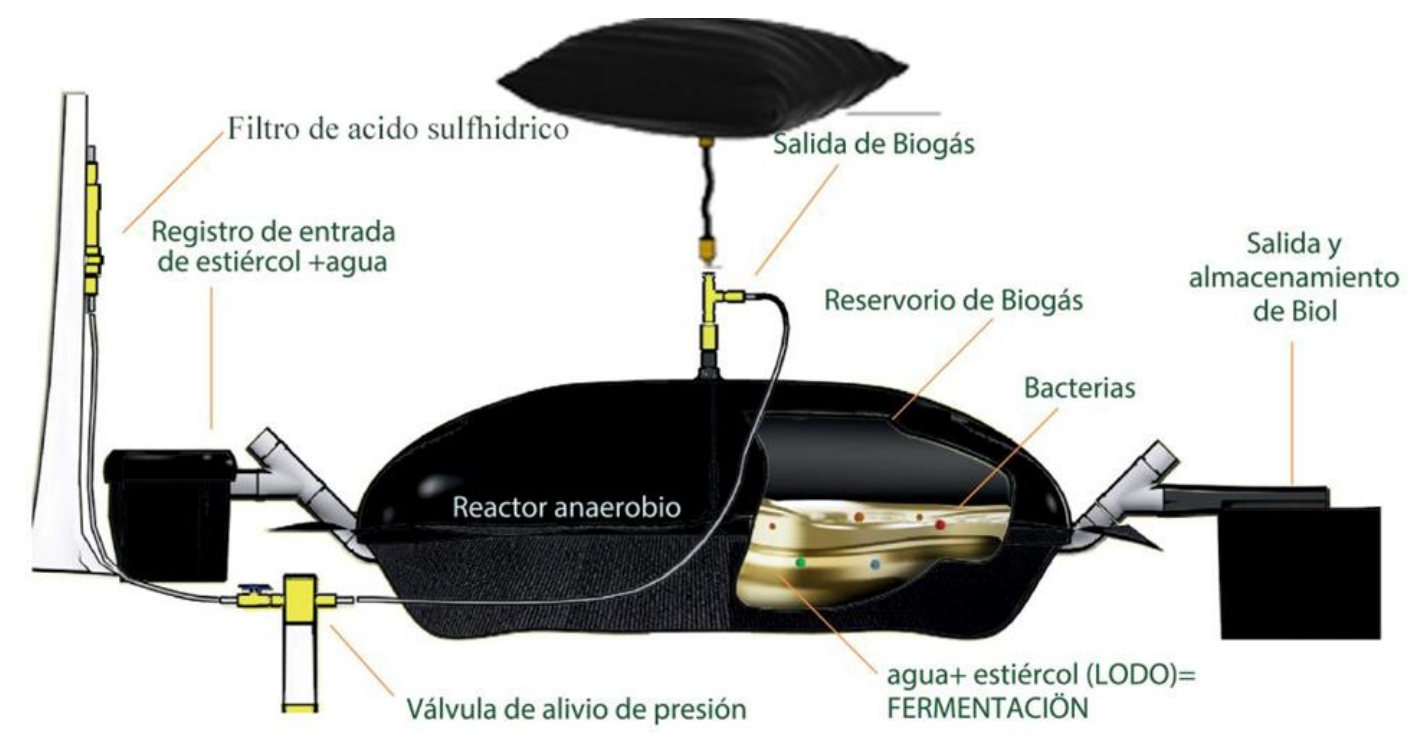

Figura 1. Diseño del biodigestor instalado para la producción de biogás en el RUPAP. Fuente. Empresa Tecnosol S. A. donante del biodigestor.

Modificaciones realizadas para la rehabilitación de la cocina industrial

La cocina industrial pertenece al comedor del RUPAP-UNI, se encontraba en desuso y deshabilitada desde hace 10 años en la bodega del comedor. Esta cocina industrial funcionaba con GLP (figura 2).

Los componentes como válvulas de apertura y cierre, conectores de suministro del gas y quemadores, se encontraban dañados y fueron reemplazados. Todos los componentes obstruidos de grasa fueron limpiados y pulidos. Se realizaron los diseños de niples y acoples. Estos fueron maquinados en los talleres de máquinas herramientas y de soldadura del RUPAP. Se cerraron los orificios de paso de gas innecesarios. Los niples y acoples se adaptaron al tubo de distribución del gas. El primer quemador u hornilla se dejó en la cocina original. El diseño final de la cocina industrial habilitada se muestra en la figura 3. 


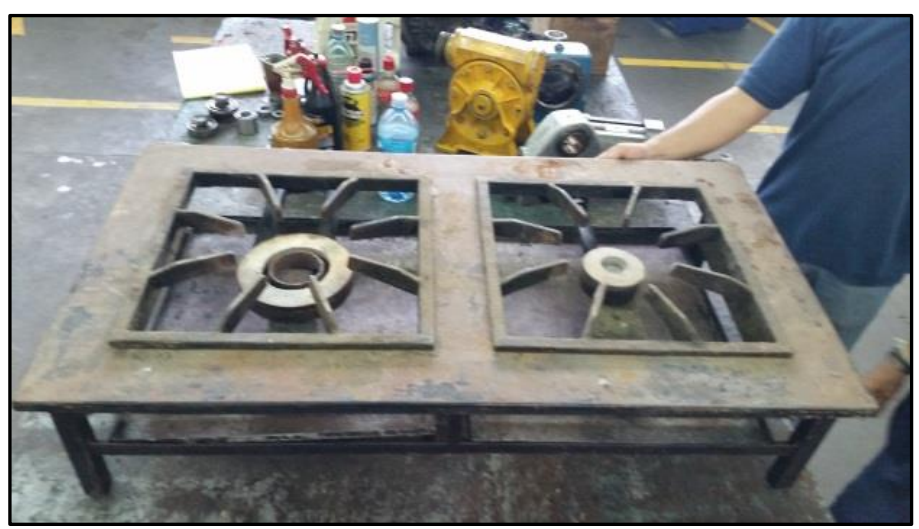

Figura 2. Estado de la cocina industrial de gas licuado de petróleo (GLP).

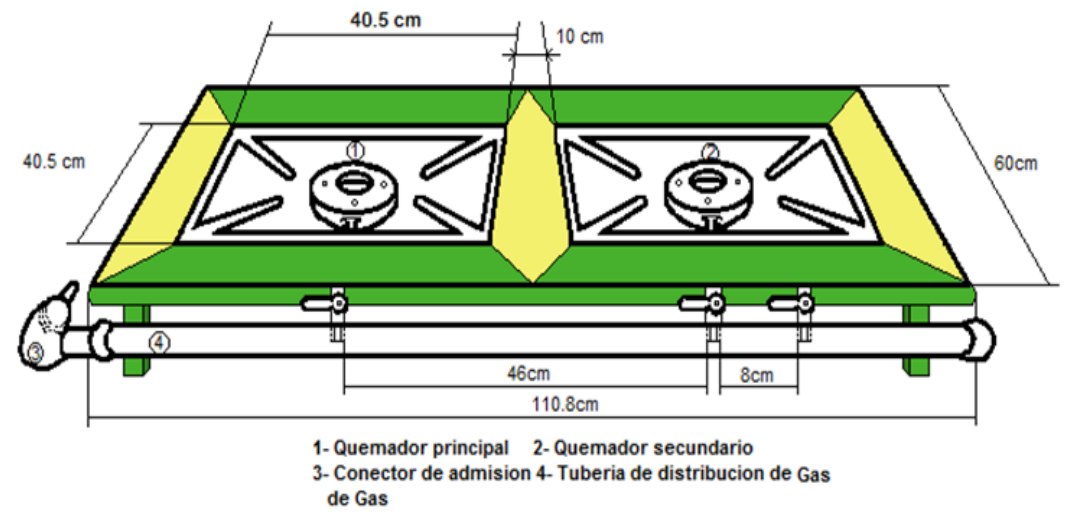

Figura 3. Diseño final de la cocina industrial utilizada en este estudio

\section{Pruebas de funcionamiento}

Una vez sustituidas todos los componentes en la cocina industrial, se realizaron las pruebas de funcionamiento. Estas consisten en encender la cocina utilizando como combustible gas licuado de petróleo o biogás.

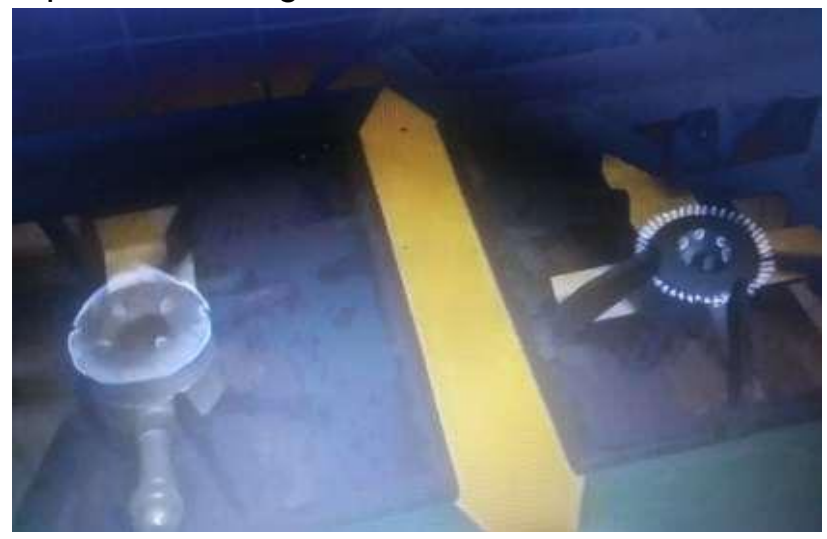

Figura 4: Quemador principal y quemador secundario encendido usando biogás.

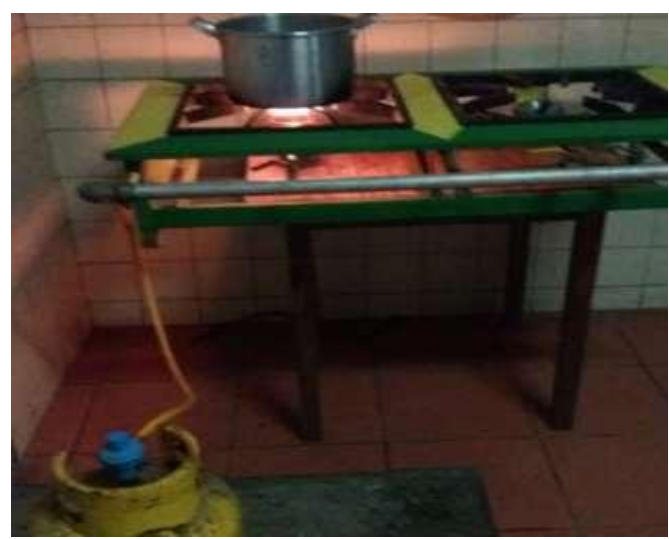

Figura 5: Cocina encendida usando gas licuado de petróleo. 
La recolección de datos se dio en el municipio de Managua, Nicaragua, en las coordenadas $12^{\circ} 08^{\prime} 11.5^{\prime \prime} \mathrm{N} 86^{\circ} 13^{\prime} 25.3^{\prime \prime} \mathrm{W}$, dentro de las instalaciones del comedor en un ambiente controlado y sin contacto con elementos exteriores (lluvias y vientos). Los datos fueron recolectados entre las 8:30 am a 10:50 am (UTC-6).

Para la obtención de datos se utilizaron instrumentos como: cronometro, pistola de temperatura laser, recipiente graduado para medir los litros de agua, dos ollas de acero y un tanque de 25 libras de gas licuado de petróleo.

El experimento consistió en colocar 5 litros de agua dentro de la olla de acero. Y seguidamente, calentar hasta la temperatura inicial de $33^{\circ} \mathrm{C}$, dando inicio al cronometraje hasta alcanzar la temperatura de ebullición para garantizar que sea una medición homogénea, se tomó la temperatura de ebullición como aquella en la que explota la primera burbuja del hervor. Se realizaron cuatro réplicas de este experimento para cada combustible: GLP y biogás. Para el procesamiento de los datos se utilizó el diseño factorial de dos factores con interacción partiendo que este diseño es completamente aleatorizado con respecto a todas las combinaciones de tratamiento. Se realizaron cuatro réplicas de este experimento para los tipos de combustible: gas licuado de petróleo y biogás. Para el procesamiento de los datos se utilizó el método de análisis de variancia, ANOVA, bifactorial con interacción con el software Statgraphics v. 15.2.14.

Durante tres días se recolectaron datos con respecto al tiempo en la que se logró llegar al punto de ebullición de cinco litros de agua, tomando en cuenta condiciones específicas en el punto en que se aplicó el experimento. Para cada punto de ebullición existe un tiempo en el que se logró alcanzar.

Respectivamente como Factor A (días) tomando tres niveles de factor correspondientes a los 3 días en que se tomó las muestras, para el Factor B (Tipos de Combustible) teniendo dos niveles de factor que serían GLP y Biogás para cada día se tomó 4 muestras, correspondientes a las dos variables resultados que son tiempo y temperatura de ebullición.

Hipótesis planteadas:

Hipótesis nula: Las interacciones del GLP y el Biogás, con respecto a la Temperatura y el Tiempo de Ebullición son iguales.

Hipótesis alternativa: Las interacciones del GLP y el Biogás, con respecto a la Temperatura y el Tiempo de Ebullición son diferentes.

\section{RESULTADOS Y DISCUSIÓN}

Para el factor tipo de combustible (TPC) se rechaza la hipótesis nula, para el factor días y la interrelación de los factores la hipótesis nula no se rechaza. Por tanto, los datos de la tabla 1 muestran que existe un efecto significativo para alcanzar la temperatura de ebullición con respecto al factor tipos de combustibles (TPC). Con el Biogás el punto de la ebullición del agua se alcanzó en mayor tiempo en comparación con el Gas Licuado de Petróleo (Figura 6). 
Tabla 1. Análisis de varianza para el punto de ebullición de acuerdo al tipo de combustible

\begin{tabular}{|l|l|l|l|l|l|l|}
\hline \multicolumn{1}{|c|}{ Fuente } & \multicolumn{1}{|c|}{$\begin{array}{c}\text { Suma de } \\
\text { cuadrados }\end{array}$} & \multicolumn{1}{|c|}{ Gl } & $\begin{array}{c}\text { Cuadrado } \\
\text { medio }\end{array}$ & $\begin{array}{c}\text { Razón } \\
\text { F }\end{array}$ & Valor-P & $\begin{array}{c}\text { Significa } \\
\text { ción }\end{array}$ \\
\hline Efectos principales & & & & & & \\
\hline A-Días & 77,0058 & 2 & 38,5029 & 1,14 & 0,2627 & NS \\
\hline B-TPC & 425,042 & 1 & 425,042 & 15,91 & $\mathbf{0 , 0 0 0 9}$ & Sig. \\
\hline Interacciones & & & & & & \\
\hline AB & 51,1658 & 2 & 25,5829 & 0,96 & 0,4025 & NS \\
\hline Residuos & 480,845 & 18 & 26,7136 & & & \\
\hline Total (Corregido) & 1034,06 & 23 & & & & \\
\hline
\end{tabular}

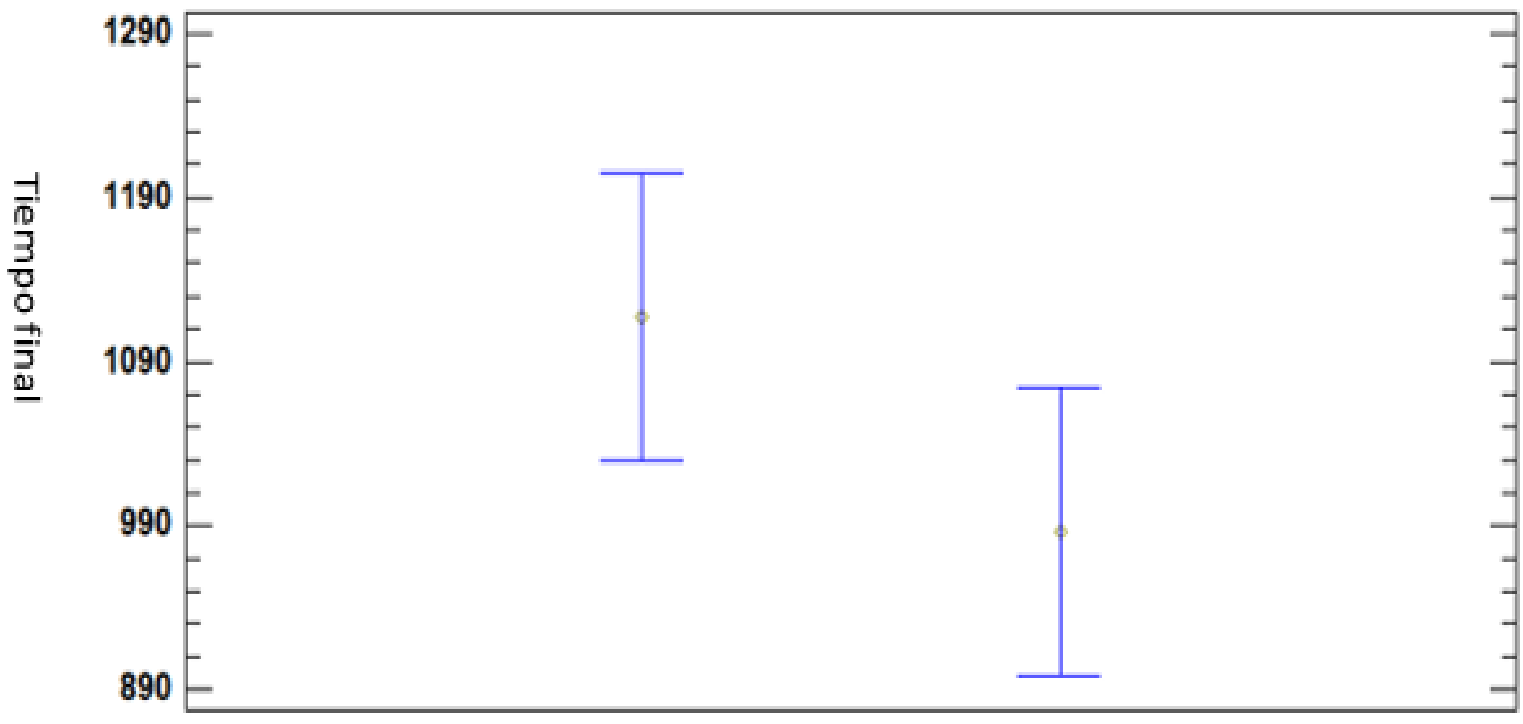

Biogás Gas licuado de petróleo

Tipo de combustibles

Figura 6. Intervalos de Confianza del tiempo de ebullición del agua con los combustibles: biogás y GLP.

Es importante destacar que al momento de alcanzar el punto de ebullición el agua, la temperatura promedio alcanzada por la llama del biogás $\left(61^{\circ} \mathrm{C}\right)$ fue menor que la del gas licuado del petróleo $\left(69^{\circ} \mathrm{C}\right)$.

Por otra parte, al analizar el tiempo final de ebullición (TMF) de los Gases, se obtuvieron los siguientes resultados, ver tabla 2 . 
María T. Castillo R.; Carlos J. Izaba U.

Tabla 2. Análisis de varianza para tiempo final de ebullición, TMF

\begin{tabular}{|l|l|l|l|l|l|}
\hline Fuente & $\begin{array}{l}\text { Suma de } \\
\text { cuadrados }\end{array}$ & Gl & $\begin{array}{l}\text { Cuadrado } \\
\text { medio }\end{array}$ & $\begin{array}{l}\text { Razón } \\
\text { F }\end{array}$ & Significación \\
\hline $\begin{array}{l}\text { Efectos } \\
\text { principales }\end{array}$ & & & & & \\
\hline A-Días & 71175,7 & 2 & 35587,8 & 0,85 & NS \\
\hline B-TPC & 103622 & 1 & 103622 & 2,48 & NS \\
\hline Interacciones AB & 52222,9 & 2 & 26111,4 & 0,63 & NS \\
\hline Residuos & 751026 & 18 & 41723,7 & & \\
\hline Total (Corregido) & 978047 & 23 & & & \\
\hline
\end{tabular}

Según los datos de la tabla 2, no existió un efecto significativo (no influyó) sobre el tiempo final de ebullición (TMF), en los días, tipos de combustible (TPC) o la interacción, la hipótesis fue nula en los 3 casos. Por consiguientes se concluye que el Biogás no muestra un efecto significativo con respecto al tiempo final (TMF) para alcanzar el punto de ebullición.

Según la gráfica de interacción (figura 7), en el día uno se observó que el tiempo final de ebullición (TMF) se prolongó para ambos combustibles, en el día dos, con el gas licuado de petróleo se alcanzó la ebullición del agua a menor tiempo que con el biogás, en el día 3 como muestra la figura, el gas licuado de petróleo demandó menos tiempo para alcanzar el hervor de agua que el biogás, lo que está relacionado con el poder calorífico.

Gráfico de Interacciones

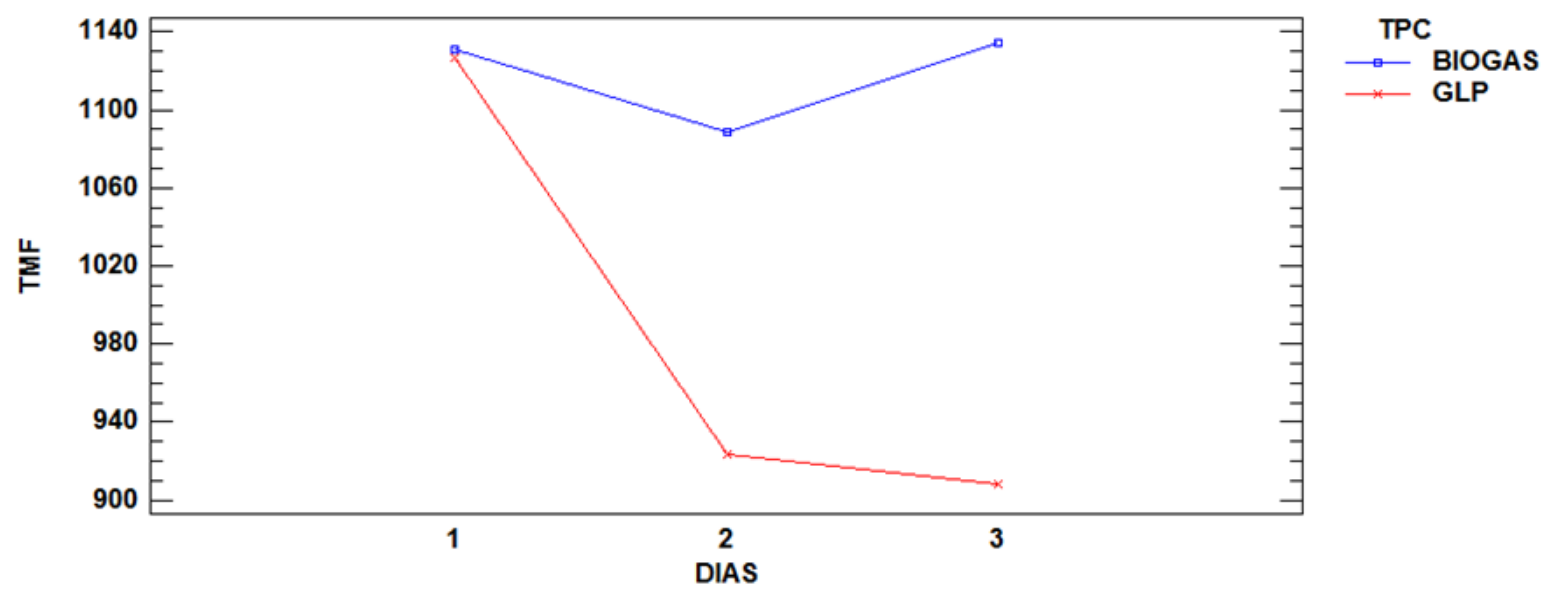

Figura 7. Gráfico de interacción de biogás y GLP.

Durante las pruebas de funcionamiento con GLP, se pudo observar manchas de hollín en la superficie de contacto de las ollas con la llama y en el caso de las pruebas realizadas con biogás no se presentaron manchas en las ollas. También se observa que la llama era azulada con puntas naranjas. Aunque Víquez (2018) encontró en una investigación que, en el consumo de biogás, el 
tamaño y color de la flama, no son indicadores para conocer la eficiencia y funcionabilidad de una cocina.

La temperatura del lugar de instalación del biodigestor influyó en la producción del biogás, la cual fue de $34^{\circ} \mathrm{C}$. A mayor temperatura, la degradación de las bacterias metanogénicas responsables de producir gas metano es más rápida y a menor temperatura, la producción es más tardía. Existen tres rangos de temperatura para los sistemas de biogás anaeróbicos: psicrófilos (por debajo de $25^{\circ} \mathrm{C}$ ), mesófilos (entre 25 y $45^{\circ} \mathrm{C}$ ), y termófilos (entre 45 y $65^{\circ} \mathrm{C}$ ). Estos rangos de temperatura facilitan el crecimiento de microbios específicos (LaGrange, 1979).

\section{CONCLUSIONES}

Los resultados obtenidos de la evaluación técnica de la cocina de gas licuado de petróleo para funcionar con biogás, indican que el diseño facilitó la adaptación a biogás, con la implementación de los cambios en el sistema de distribución del gas, quemadores de GLP a Biogás, válvulas de alimentación, cierre de combustible y el cambio de accesorios necesarios. Es importante resaltar que, con el biogás, el agua alcanzó su punto de ebullición en un mayor tiempo, en comparación con el gas licuado de petróleo (más eficiente).

\section{REFERENCIAS}

Antonio, E., \& Aguilera, R. (2017). Generación de biogás mediante el proceso de digestión anaerobia, a partir del aprovechamiento de sustratos orgánicos. 6(24), 60-77.

Barrena, M., Hellenthal, M., \& Ordinola, C. (2014). Rendimiento del biogas como combustible para cocina e iluminación producido en biodigestor tubular en la Providencia, Luya - Amazonas Performance of biogas as fuel for kitchen and lighting produced in tubular biodigester in Providencia, Luya - Amazonas. 3(1), 117-124. https://doi.org/10.25127/indes.201501.0

Barrera-Cardoso1, D. C. E. L., Https://orcid.org/0000-0003-0207-4188, *, Odales-Bernal1, Ms. L., Https://orcid.org/0000-0001-7907-2805, Carabeo-Pérez1, L. A., Https://orcid.org/0000-00030129-5544, Alba-Reyes1, Ms. Y., Https://orcid.org/0000-0002-9816-3101, Hermida-García1, Ms. F. O., \& Https://orcid.org/0000-0002-7645-5947. (2020). Recopilación de aspectos teóricos sobre las tecnologías de producción de biogás a escala rural. Tecnología Quimica, 2224-6185, 40(2), 2020.

Ferrer, Yoandy; Pérez, H. (2010). Los microorganismos en la digestión anaerobia y la producción de biogás. Consideraciones en la elección del inóculo para el mejoramiento de la calidad y el rendimiento. ICIDCA : Sobre Los Derivados de La Caña de Azúcar, 43(1), 9-20.

GEF, MINENERGIA. PNUD, F. (n.d.). Manual del biogás (G. E. Energía, Ministerio de Desarrollo, Programa de las Naciones Unidas para lal Agricultura, Organización de las Naciones Unidas para la Alimentación y la Facility (ed.); Proyecto C).

Lagrange, B. (1979). Biomethane. Principes, Techniques, Utilisation. Vol. 2. Edisual / Energies alternatives. 
Luis RodriguezFrancisco Javier. (2010). Puesta en marcha de un Laboratorio para la producción de Biogás en Nicaragua. Universidad Carlos 3 de Madrid.

Martina, Pablo | García Solá, Emilio | Corace, Juan José | Aeberhard, R., \& 2006. (2006). PROPUESTA DE UN MÉTODO EXPERIMENTAL ALTERNATIVO PARA LA DETERMINACIÓN DEL PODER CALORÍFICO DEL BIOGAS. Avances En Energías Renovables y Medio Ambiente, 10(ISSN: 0329-5184), 1-3. http://sedici.unlp.edu.ar/handle/10915/88667

Miguel Barrena , Jóhmer Julca , Monika Hellenthal, C. O. (2017). Rendimiento del biogas como combustible para cocina e iluminación. 3(1), 117-124. https://doi.org/10.25127

Singh, R. B. (1974). Bio-gas Plant: Generating Methane from organic Wastes. Gober Gas Plant Research Station, Ajitmal.

SNV. (n.d.). National Biogas Programme - Nicaragua. https://snv.org/project/national-biogasprogramme-nicaragua

Werner, E. (1983). Producciòn de energìa utilizando desperdicios agrìcolas. 1.

\section{AGRADECIMIENTOS}

Se agradece a la Vice rectoría de Investigación, Desarrollo e Innovación, por la oportunidad que brindó a lograr la realización de este proyecto de Innovación Tecnológica en la Facultad de Tecnología de la Industria, UNI-RUPAP. A la Empresa Tecnosol S. A. por la donación del biodigestor a la Facultad de Tecnología de la Industria, para poder hacer posible este proyecto.

\section{SEMBLANZA DE LOS AUTORES}

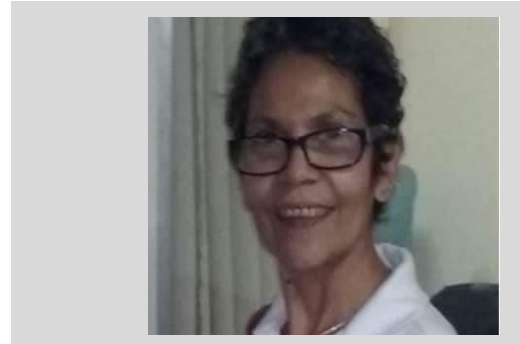

María Teresa Castillo Rayo: Ingeniero Mecánico, Máster en Energías Renovables. Especialistas en energías, Innovadora de la Universidad Nacional de Ingeniería. Recinto Pedro Arauz Palacio, Facultad de Tecnologia de la Industria. E-mail: maria.castillo@fti.uni.edu.ni

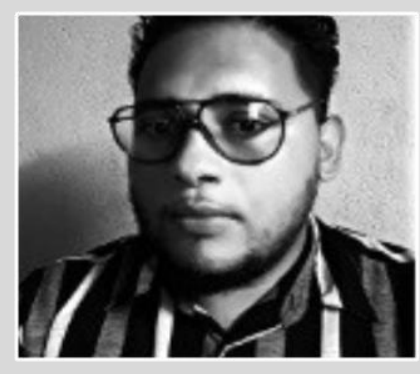

Carlos José Izaba-Umaña: Ingeniero Mecánico. Egresado de la Facultad de Tecnología de la Industria, innovador en formación. E-mail: cjumanai@gmail.com 